\title{
Critical Care Nurses as Frontline Warriors During COVID-19 in Pakistan
}

\author{
Shaista MEGHANI, PhD Student, MScN, BScN, RN, RM, a $\odot$ Nasreen LALANI, PhD, MScN, RN $\odot$
}

Background: The COVID-19 pandemic resulted in several short-term and long-term impacts on the physical, social, and psychological health of every individual globally, especially among frontline workers including nurses working in the critical care settings. In Pakistan, 85,264 confirmed cases have been identified and 1,770 deaths are reported so far. The death rate is 2.0\% as compared to Europe (14.6\%) and the United States (5.7\%) per 100,000 population. Frontline workers are the most vulnerable population during this pandemic. Nearly 440 frontline staff including nurses, doctors, and other health workers have been infected with COVID-19 with 8 confirmed deaths reported in different provinces of Pakistan. These numbers are continuously increasing posing a serious threat for the health and well-being of the healthcare professionals especially nurses working in the critical care settings. Objective: The paper outlines the challenges and experiences of critical care nurses working in acute hospital settings of a low resourced country Pakistan during a pandemic. Methods: Literature search using CINAHL, MEDLINE, PubMed databases, local and international news papers, magazines, websites, international nursing colleagues and personal experiences/insights are included in the paper. Results: Findings include common challenges such as lack of staff, lack of personal protective equipment ( $P P E$ ), limited knowledge regarding standard infection control practices, isolation protocols, lack of administrative support, transportation, accommodation, childcare facility, and so forth. As a result, most nurses are reporting symptoms of fear, anxiety, depression, post-traumatic symptoms, spiritual, and moral distress. Nurses often become targets of violence and harassment by the general public in the Pakistani healthcare system, due to lack of awareness, cultural beliefs, low status/image of nurses, low literacy levels, and poverty. Conclusion: Targeted interventions and policies are needed to maintain safety and protect physical, social, psychological, and spiritual health and well-being of nurses. Health authorities in Pakistan should take the responsibility in creating awareness, providing adequate guidance, and support to enhance nurses' well-being and quality of life during the pandemic.

Keywords: COVID-19 pandemic, critical care nurses, challenges, experiences, Pakistan healthcare system

The COVID-19 pandemic turned out to be the biggest turmoil of the year 2020. The experience of this shattering outburst is creating short-term and long-term impact on the physical, social, and psychological health of every individual globally (Rana, Mukhtar, \& Mukhtar, 2020). According to World Health Organization (WHO), total positive cases and deaths around

\footnotetext{
a University of Alberta, Edmonton, Canada, E-mail: shaista@ualberta.ca

${ }^{b}$ Assistant Professor, Purdue University, IN, USA, E-mail: lalanin@purdue.edu
} 
the world are 5,596,550 and 353,373 respectively (WHO, 2020). In Pakistan, 85,264 confirmed cases have been identified and 1,770 deaths are reported so far (Government of Pakistan, 2020). Despite 200 million Pakistani population and their overburdened healthcare systems, the death rate has been $2.0 \%$ per 100,000 population (Johns Hopkins, 2020), which is lower than in Europe and the United States (14.6\% and 5.7\% per 100,000 population respectively). However, numbers of suspected, infected, and death rates of Pakistani population seem underestimated, and the real picture may be hidden by limited resources and test kits available in the country (Waris et al., 2020). The numbers reported also include healthcare professionals in general, and nursing staff in particular, who have also been affected by the wake of this deadly virus. Globally, 90,000 health workers are positive with COVID19 and more than 600 nurses have lost their lives (Dawn News, 2020b). Whereas, in Pakistan, more than 440 frontline staff including nurses, doctors, and other health workers have been infected with COVID-19 with 8 confirmed deaths reported in different provinces of Pakistan (Dawn News, 2020a). Out of these workers, 216 are doctors, 67 are nurses, and 161 are other medical workers. These numbers are increasing on a daily basis as time goes by (Butt, 2020; Dawn News, 2020c).

\section{HEALTHCARE SYSTEM CHALLENGES DURING COVID-19 IN PAKISTAN}

The healthcare system of Pakistan has remained challenged with problems of scarcity of resources, insufficient and untrained human personnel, shortage of healthcare professionals, structural mismanagement, and gender insensitivity (Hassan, Mahmood, \& Bukhsh, 2017; Khan, 2019). Pakistan has remained deficient in human health resources. The nurse to patient ratio recommended by the Pakistan Nursing Council is 1:10, whereas the actual ratio is $1: 20$, at present (Kumar \& Bano, 2017). Over the last few decades, the quality provision of public health services has been decreasing. There is an absence of programming and training of healthcare workers on communicable, noncommunicable, and pandemic diseases, at provincial and federal levels (Khan, 2019). The healthcare services are not adequately prepared for the pandemic or disaster management and its recovery (Saqlain, Munir, Ahmed, Tahir, \& Kamran, 2020). With the novel SARS-cov-2 virus outbreak, Pakistan healthcare authorities lacked emergency management plan to deal with this crisis from the initial stage (Khan, Khan, Maqsood, Hussain, \& Zeeshan, 2020; Rana et al., 2020).

The healthcare services in Pakistan have been overwhelmed during COVID-19, and they are facing an even greater shortage of healthcare workers, due to the increased demands on the system. For 200 million Pakistani population, there is only one doctor for 1,073 individuals and 90,276 nurses for the overall population (Mashhadi, Hamid, Roshan, \& Fawad, 2016; Meghani \& Sajwani, 2013). The rate of nurses per thousand people is 0.7 in Pakistan, compared to an average of 11.0 in high-income countries, and to 1.0 in low-income countries (World Bank, 2018). Taking into account healthcare personnel shortages and the immense workload of these professionals in the current outbreak of COVID-19 in Pakistan, compromises in the status of care have been difficult to avoid. At present, for every 10,000 people, there are only 9.8 physicians, 5 nurses, and 6 hospital beds available in Pakistan, according to a recent United Nations Development Program (UNDP) report (Gulf News, 2020). A lack of support by the local government delayed the provision of basic amenities and resources to the communities, and no plan was in place for the relief of the overwhelmed healthcare system and staff shortages in response to the pandemic (Sheikh, 2020). Minimal investment in healthcare services has been undertaken by the federal and provincial government. For instance, PKR 50 billion was reserved for purchasing medical supplies and but half of the 2,200 ventilators allocated to treat SARS-cov-2 infected patients were functional (Sheikh, 2020). The short distribution and utilization of the medical supplies and equipment 
for the 200 million population dealing the outburst of corona virus pandemic in Pakistan has not well justified. Additionally, there are limited testing kits and hospital beds available to accommodate the infected patients. Many tertiary care hospitals in Pakistan have suspended corona virus testing and patients' admission in the hospital due to limited capacity of accommodation in emergency and intensive cares (Latif, 2020). Hospitals are discouraging people suffering from illnesses other than COVID-19 from visiting the facility and encouraging them to use telehealth services. However, due to poverty and low literacy, the use and access to technology among the general population remains questionable (Rehman, Jingdong, \& Hussain, 2015). Given the above challenges, the country lacks a health system that could adequately manage and timely address the detection and treatment of such large-scale outbreaks (Sheikh, 2020).

\section{CRITICAL CARE NURSES EXPERIENCES WITH COVID-1 9 IN PAKISTAN}

Nurses as frontline workers are the most vulnerable group during the pandemic in Pakistan. Nurses are often the last thread of compassion for patients. From the emergency door to the intensive care, they are the ones doing screening, implementing triage protocols, providing care to critically ill patients/families, and communicating with dying patients/families. Common challenges faced by critical care nurses in Pakistan working in tertiary care hospitals include lack of staff, clinical resources, adequate infection control protocols, and of leadership support (Samuel, Sehar, Afzal, \& Gilani, 2018). As a result, nurses are experiencing lot of physical and psychological distress. Most frontline workers including nurses are reporting symptoms of fear, anxiety, depression, post-traumatic symptoms, spiritual, and moral distress, affecting their overall health and well-being (Dawn, 2020a). The experience of critical care nurses with working in isolation and complex care units, wearing full protective gear for 8-10 hours per shift, providing care to infected, critical, and dying patients, while also listening to the concerns of patients and their families are major contributors causing poor mental well-being of nurses. Moreover, nurses are facing additional challenges in terms of lack of personal protective equipment (PPE), limited knowledge regarding standard infection control practices, isolation protocols, lack of administrative support, transportation, accommodation, childcare facility, and so forth (Hamid, 2016). Many nurses are unable to see their children and loved ones' after work in order to prevent the spread of the virus in their families and communities. Nurses' also face financial constraints, not getting any incentives for working harder and doing extra shifts in the units, and the limited recognition and appreciation in the healthcare institutions (Meghani \& Sajwani, 2013). All these challenges further add to the frustration, poor physical and mental well-being and burnout among nurses working as frontline workers in various critical care settings of the hospitals.

Moral distress is common among the critical care nurses managing the huge influx of complex and infected patients. Nurses are encountering various kinds of ethical issues/dilemmas dealing with huge influx of infected patients on a daily basis in the intensive care units. Other than the reasons given above such as lack of PPE, unavailability of the testing kits, unpreparedness of disaster management plan, inadequate support of response and recovery, nurses also face harassment and other similarly challenging situations while dealing with the distressed patients and families. Nurses often become targets of violence and harassment by the general public in the Pakistani healthcare system, commonly due to lack of awareness, cultural beliefs, low status/image of nurses, lack of leadership and administrative support, low literacy levels, and poverty (Meghani \& Sajwani, 2013). Another major concern is that, due to the shortage of nurses in the country, the majority of nurses working in intensive care settings are novice nurses with no or less clinical experience, and therefore are more vulnerable to moral and psychological distress. Due to lack of 
experience and increased workload, as well as the dearth of training and appropriate support, there is an increased risk of errors, which can result in harm for themselves, as well as for patients and families (Das, Baby, \& Barik, 2016). All these issues are critical and need to be addressed timely to reduce harm and promote the quality and safety for all in Pakistani healthcare.

\section{WAY FORWARD}

Pandemics usually expose the realities and the inadequacies of the healthcare system response of many countries' and of their measures for healthcare, economic, and social protection. On the other hand, it also provides an opportunity to learn, improve, and prepare response system for future pandemic situations. Nurses as frontline workers are often vulnerable and addressing these vulnerabilities should be the foremost concern for healthcare system stakeholders. Maintaining safety and protecting physical, social, psychological, and spiritual health and well-being of nurses should be the utmost priority. Adequate awareness, guidance, and support should be provided for nurses at all levels (Shen et al., 2020). The government, health and nursing regulatory bodies as well as the local health authorities of Pakistan should investigate the experiences of hardship and suffering causing ethical and moral distress among nurses during the pandemic, in order to enhance their ability to provide high quality, safe and sensitive care. The healthcare authorities and hospital administration should ensure an adequate supply of PPE, and other resources to support nurses working in the healthcare facilities during the pandemic (Mukhtar, 2020). Training and education measures should be strengthened, including isolation protocols, use of PPE, medical waste management, emergency management, self-protection manuals, and so on. One of the tertiary care of hospitals of Karachi, Pakistan, the Aga Khan University Hospital (AKUH), in collaboration with the university and Sindh Government, have taken the initiative to provide cost-free training and technical assistance to doctors and critical care nurses dealing with severely ill COVID-19 patients (Aga Khan University [AKU], 2020). On the other hand, specific measures should be in place to protect psychological and spiritual wellbeing of nurses such as Psychological First Aid (PFA) training and other mental health resources (Lalani \& Drolet, 2020). Leadership and hospital authorities need to enforce measures to protect nurses from facing harassment and other issues in the workplace while ensuring workforce security and protection. Having a right action plan will prepare, protect, empower, and advocate healthcare professionals, their families, and community at large during this pandemic crisis.

\section{REFERENCES}

Aga Khan University. (2020, May 5). AKU commences courses on COVID-19 critical care. Retrieved from https://www.aku.edu/news/P ages/News_Details.aspx?nid=NEWS-002174

Butt, K. (2020). Virus cases among Pakistan's medical workers increase. Almost 200 healthcare worker test positive for COVID-19 within a week. Retrieved from https://www.aa.com. tr/en/asia-pacific/virus-cases-among-pakistan s-medical-workers-increase/1826007

Das, S., Baby, P., \& Barik, B. K. (2016). Factors triggering intensive care unit stress and its effects on registered novice nurses. International Journal of Pharmaceutical Sciences Review and Research, 38(1), 95-101. Retrieved from www.globalresearchonline. net

Dawn News. (2020a, May 8). Over 90,000 health workers infected with covid-19 worldwide: Nurses group worldDAWN.COM. Retrieved from https://www.dawn.com/news/155501

Dawn News. (2020b). Fighting on the front line, at least 253 healthcare workers infected with covid-19 in Pakistan. Retrieved from https:// www.dawn.com/news/1551853/fighting-onthe-front-line-at-least-253-healthcare-workers -infected-with-covid-19-in-pakistan-so-far

Dawn News. (2020c). Infection amongst healthcare workers increase by $75 p c$ in a week. Retrieved from https://www.dawn.com/news/ 1553678 
Government of Pakistan. (2020). COVID-19 health advisory platform by ministry of national health services regulations and coordination. Retrieved from http://covid.gov.pk/

Gulf News. (2020). Why Pakistan's healthcare workers are against easing the COVID-19 lockdown. Retrieved from https://gulfnews.c om/world/asia/pakistan/why-pakistans-healt h-workers-are-against-easing-the-covid-19-loc kdown-1.1589469775577

Hamid, S. (2016). Ethical issues faced by nurses during nursing practice in district Layyah, Pakistan. Diversity \& Equality in Health and Care, 13(4), 302-308. https://doi.org/10.21767/2049-5471.100068

Hassan, A., Mahmood, K., \& Bukhsh, H. A. (2017). Healthcare system of Pakistan. IJARP, 1(4), 170-173.

Johns Hopkins. (2020, June 08). Maps \& trends: Mortality analysis. Retrieved from https://cor onavirus.jhu.edu/data/mortality

Lalani, N., \& Drolet, J. (2020). Effectiveness of psychological first aid training for social work students, practitioners and human service professionals in Alberta, Canada. Journal of Practice Teaching \& Learning, 17(1), 1-15.

Khan, S. A. (2019). Situation analysis of healthcare system of Pakistan: Post 18 amendments. Health Care Current Reviews, 7(3), 1-9. https://doi.org/10.35248/23754273.19.07.244

Khan, S., Khan, M., Maqsood, K., Hussain, T., \& Zeeshan, M. (2020). Is Pakistan prepared for the COVID 19 epidemic? A questionnaire based survey. Journal of Medical Virology, 19. https://doi.org/10.1002/jmv.25814

Kumar, S., \& Bano, S. (2017). Comparison and analysis of health care delivery systems: Pakistan versus Bangladesh. Journal of Hospital \& Medical Management, 3, 1-7. https://doi.org/10.4172/2471-9781.100020

Latif, A. (2020). Pakistan's health system braces for COVID-19 peak. Retrieved from https://w ww.aa.com.tr/en/asia-pacific/pakistans-healt h-system-braces-for-covid-19-peak/1867396

Mashhadi, S. F., Hamid, S., Roshan, R., \& Fawad, A. (2016). Healthcare in Pakistan-a systems perspective. Pakistan Armed Forces Medical Journal, 66(1), 136-142.

Meghani, S. R., \& Sajwani, S. (2013). Nursing: A profession in need in Pakistan. IManager's Journal on Nursing, 3(3), 1. https://doi.org/10.26634/jnur.3.3.2487

Mukhtar, P. S. (2020). Mental wellbeing of nursing staff during the COVID19 outbreak: A cultural perspective. Journal of Emergency Nursing, 1-2. https://doi.org/10.1016/j.jen.2020.04.003

Rana, W., Mukhtar, S., \& Mukhtar, S. (2020). Mental health of medical workers in Pakistan during the pandemic COVID-19 outbreak. Asian Journal of Psychiatry, 51, 102080. https://doi.org/10.1016/j.ajp.2020.102080

Rehman, A., Jingdong, L., \& Hussain, I. (2015). The province-wise literacy rate in Pakistan and its impact on the economy. Pacific Science Review B: Humanities and Social Sciences, 1(3), 140-144. https://doi.org/10.1016/j.psrb.2016.09.001

Samuel, H., Sehar, S., Afzal, M., \& Gilani, S. A. (2018). Influence of supportive leadership on nursing clinical decision making in critical care units at tertiary care hospital Lahore. International Journal of Nursing, 5(2), 45-71. https://doi.org/10.15640/ijn.v5n2a5

Saqlain, M., Munir, M. M., Ahmed, A., Tahir, A. H., \& Kamran, S. (2020). Is Pakistan prepared to tackle the coronavirus epidemic? Drugs \& Therapy Perspectives, 1-2. https://doi.org/10.1007/s40267-020-00721-1

Sheikh, H. (2020, April 6). COVID-19: Pakistan's preparations and response. International Growth Center. Retrieved from https://www.t heigc.org/blog/covid-19-pakistans-preparatio ns-and-response/

Shen, X., Zou, X., Zhong, X., Yan, J., \& Li, L. (2020). Psychological stress of ICU nurses in the time of COVID-19. Critical Care, 24 (200). 1-3. doi: 10.1186/s13054-020-02926-2.

Waris, A., Atta, U. K., Ali, M., Asmat, A., \& Baset, A. (2020). COVID-19 outbreak: Current scenario of Pakistan. New Microbes and New Infections, 35(20), 100681. https://doi.org/10.1016/j.nmni.2020.100681 
World Health Organization. (2020). Getting your workplace ready for COVID-19. Retrieved from https:/www.who.int/docs/default-sourc e/coronaviruse/getting-workplace-ready-for-c ovid-19.pdf

World Bank. (2018). World Health Organization's Global Health Workforce Statistics, OECD, supplemented by country data. Retrieved from https://data.worldbank.org/indicator/S H.MED.NUMW.P3
Disclosure. The authors have no relevant financial interest or affiliations with any commercial interests related to the subjects discussed within this article.

Funding. The author(s) received no specific grant or financial support for the research, authorship, and/or publication of this article. 